\title{
Evidence-Based Neonatal Care
}

\author{
Anucha Thatrimontrichai, M.D.
}

Division of Neonatology, Department of Pediatrics, Faculty of Medicine, Prince of Songkla University, Hat Yai, Songkhla 90110, Thailand.

Received 4 December 2018 • Revised 21 February 2019 • Accepted 10 April 2019 • Published online 13 May 2019

\section{Abstract:}

Aging societies are developing around the world while the number of newborns is decreasing. The best neonatal care is a crucial issue since prematurity is surging along with high mortality and morbidity in developing countries. However, the basic areas of evidence-based practice in neonatal care still have limited information because both the shortand long-term outcomes of this fragile population need to be considered. Sophisticated neonatal care is a new topic for improvement of survival and long-term neurodevelopmental outcomes. Randomized controlled trials and metaanalyses in neonatal care were reviewed and the local epidemiology was integrated to implement evidence-based neonatal care.

Keywords: evidence-based practice, neonatal intensive care unit, newborn, perinatal care

Contact: Asst. Prof. Anucha Thatrimontrichai, M.D.

Division of Neonatology, Department of Pediatrics, Faculty of Medicine,

Prince of Songkla University, Hat Yai, Songkhla 90110, Thailand.

E-mail: tanucha@medicine.psu.ac.th
J Health Sci Med Res 2019;37(3):163-169 doi: $10.31584 /$ jhsmr.201951 www.jhsmr.org 


\section{Introduction}

Knowledge of neonatal practice is rapid growing in evidence-based medicine. Many clinical trials were done to determine the best neonatal care available and decrease the mortality and morbidities, especially in prematurity. ${ }^{1,2}$ Preterm neonates present vast and challenging problems for clinicians, pediatricians, and neonatal nurses. ${ }^{2}$ We reviewed clinical trials from randomized controlled trials and meta-analyses that included neurologic, respiratory, cardiovascular, gastrointestinal tract disorders, and sepsis in neonates.

\section{Neurologic disorders}

Neonatal survivals have improved around the world, especially in very low birth weight infants (VLBW, birth weight less than 1,500 grams); however, neurodevelopmental outcomes are challenging for neonatal teams. Neuroprotective benefits in prematurity and asphyxia are a hope for the parents and clinicians.

Antenatal magnesium sulphate $\left(\mathrm{MgSO}_{4}\right)$ for fetal neuroprotection can be given close to the planned or expected preterm birth to reduce the burden of death and cerebral palsy $(\mathrm{CP})$ in very preterm infants. The loading dose of $\mathrm{MgSO}_{4}$ in the clinical trials was 4 grams with or without a 1-2 gram(s)/hour as the maintenance dose. There was a significant reduction in the risk of death or $\mathrm{CP}$ with $\mathrm{MgSO}_{4}$ treatment in preterm births (<37 weeks' gestation) compared with no treatment [relative risk $(95 \%$ confidence interval), RR (95\% Cl) $0.86(0.75,0.99)]$. Moreover, a strong protective effect from $\mathrm{MgSO}_{4}$ treatment was found in CP survivors $[\mathrm{RR}(95 \% \mathrm{Cl}) 0.68(0.53,0.87)]^{3}$ and in moderate to severe CP babies who were almost <34 weeks' gestation the protective effect was from $2.1 \%$ to $1.3 \%$ [RR $(95 \% \mathrm{Cl}) 0.61(0.42,0.89)] .{ }^{4}$ The American College of Obstetricians and Gynecologists and the Society for Maternal-Fetal Medicine support the short-term use of magnesium sulfate in fetal neuroprotection before anti- cipated early preterm (less than 32 weeks of gestation) delivery. ${ }^{5}$ Routine practice should be considered from the aspects of benefit or incidence of outcome. If the incidence of moderate to severe CP in your hospital is less than $1.3 \%$, routine prophylaxis in a fetus who is less than 34 weeks may not be needed. Early prophylactic therapy using recombinant human erythropoietin (rhEPO) in preterm infants after birth (almost less than 32 weeks' gestation within the first 48-96 hours and applied in lower doses 1,200-1,750 IU/kg per week) reduced the incidence of children with Mental Developmental Index (MDI)<70 from $15.7 \%$ to $8.4 \%$ at 18 to 24 months of corrected age $[R R(95 \% \mathrm{Cl}) 0.51(0.31,0.81)]{ }^{6}$ Besides antenatal $\mathrm{MgSO}_{4}$ and neonatal rhEPO, "prophylactic antibiotics with intact membranes" or "repeat doses compared with a single course of antenatal corticosteroids" for women at risk of preterm labor do not clearly impact fetal neuroprotection. ${ }^{7}$

Therapeutic hypothermia (core temperature 33$34{ }^{\circ} \mathrm{C}$ within 6-hour postnatal age for 72 hours followed by re-warming at $0.5{ }^{\circ} \mathrm{C}$ per hour) for $\geq 35$ weeks' gestation neonates with evidence of intrapartum asphyxia and moderate to severe encephalopathy reduced the mortality or major neurodevelopmental disability at 18 months of age by $61.4 \%$ to $46.0 \%$ [RR $(95 \% \mathrm{Cl}) 0.75(0.68$, 0.83)] but there were significant statistical differences of adverse effects that increased sinus bradycardia and thrombocytopenia in the hypothermia group. ${ }^{8}$ However, cooling to lower than $33.5^{\circ} \mathrm{C}$ or cooling for longer than 72 hours initiated at 6 to 24 hours after birth did not decrease death or moderate to severe disability at 18 months of age..$^{9,10}$ The long-term outcome of patients who survived total body hypothermia at 6 to 7 years of age had an intelligence quotient score of $\geq 85$ or more [RR $(95 \% \mathrm{Cl})$ $1.31(1.01,1.71)$ ] from $39.4 \%$ to $51.7 \% .^{11}$ The use of adjunct therapies, that include xenon, darbepoetin, erythropoietin, topiramate, levetiracetam, phenobarbital, $\mathrm{N}$-acetylcysteine or melatonin, needs more new clinical trials for moderate to severe encephalopathy. 
In conclusion, antenatal $\mathrm{MgSO}_{4}$ and neonatal rhEPO are the neuroprotections in the preterm fetus and neonate as well as moderate to severe CP ( $<34$ weeks) and neurocognitive outcome ( $<32$ weeks), respectively. Therapeutic hypothermia ( $\geq 35$ weeks) prevented death and neurocognitive outcomes in both the short- and longterm studies.

\section{Respiratory disorders}

Respiratory distress is the most common problem in the neonatal intensive care unit (NICU) which includes bronchopulmonary dysplasia (BPD), apnea of prematurity, and use of non-invasive ventilation (NIV). Prevention of long-term respiratory complications reduces mortality, home therapy, length of stay, and hospital cost.

Systemic postnatal corticosteroids prevented BPD in preterm infants ( $<37$ weeks) but we should be aware of the incidence of $\mathrm{CP}$ if corticosteroids are commenced within the first seven days of life. ${ }^{12,13}$ Inhaled postnatal corticosteroids prevented BPD among survivors in VLBW infants particularly in patients who began during the first two weeks after birth ${ }^{14}$ but there was no significant difference if started after the first week of life. ${ }^{15}$ Nonetheless, there is no evidence that inhaled corticosteroids are better than systemic corticosteroids for ventilatordependent preterm infants. ${ }^{16}$

Methylxanthine therapy reduced apnea and the use of intermittent positive pressure ventilation (IPPV) in the first two to seven days in preterm infants with recurrent apnea. ${ }^{17}$ Caffeine prevented postoperative apnea and bradycardia and episodes of oxygen desaturation in growing preterm infants who underwent general anesthesia for surgery. ${ }^{18}$ Methylxanthines increased the chances of successful extubation of preterm infants within one week of age..$^{19}$ The results of this review did not support the use of prophylactic caffeine for preterm infants at risk of apnea. $^{20}$
In the Caffeine for Apnea of Prematurity (CAP) trial, caffeine citrate $(20 \mathrm{mg} / \mathrm{kg}$ for loading then $5-10 \mathrm{mg} / \mathrm{kg}$ for maintenance, dose of caffeine base=half dose of caffeine citrate) therapy for apnea of prematurity reduced the rates of bronchopulmonary dysplasia ${ }^{21}$, and improved the rate of survival without neurodevelopmental disability [cerebral palsy and cognitive delay $(\mathrm{MDI}<85)$ ] at 18 months. ${ }^{22}$ Neonatal caffeine therapy was no longer associated with a significantly improved rate of survival without disability in children with VLBWs who were assessed at 5 years. ${ }^{23}$ Caffeine therapy for apnea of prematurity did not significantly reduce the combined rate of academic, motor or behavioral impairments but was associated with a reduced risk of motor impairment in 11-year-old children with VLBW. ${ }^{24}$ Neonatal caffeine therapy for apnea of prematurity improved the visuomotor, visuoperceptual and visuospatial abilities at the age of 11 years. ${ }^{25}$

NIV modalities, which included nasal continuous positive airway pressure (nCPAP), nasal biphasic positive airway pressure (nBiPAP), and nasal IPPV (nIPPV), prevented reintubation in the NICU. A recent metaanalysis reported that the nIPPV and nBiPAP modes demonstrated superiority to nCPAP in preventing extubation failure in preterm neonates. ${ }^{26}$ Nasal high frequency oscillation (nHFO) is a relatively new mode of NIV in neonates. $^{27,28}$ nHFO is the application of a bias flow that generates a continuous distending positive pressure with superimposed oscillations which have a constant frequency and an active expiratory phase. The nHFO mode mixes and matches together the benefits of HFO [no need for synchronization and high carbon dioxide $\left(\mathrm{CO}_{2}\right)$ clearance] and nCPAP (increase in functional residual capacity to im prove oxygenation). ${ }^{29,30}$ Heated humidified high-flow nasal cannula (HHHFNC) are increasingly being used as a form of NIV for preterm infants. HHHFNC has similar rates of efficacy to other forms of NIV in preterm infants for preventing treatment failure, BPD and death. However, 
most evidence is available for the HHHHFNC use as postextubation support. However, further research is needed to study the different modes of NIV for the prevention of extubation failure.

In conclusion, systemic corticosteroids after 1 week and inhaled corticosteroids during the first two weeks can prevent BPD in preterm infants. Methylxanthine therapy reduces apnea, use of IPPV ventilation, and short- and long-term neurodevelopmental disability. Nasal IPPV and BiPAP are more effective in preventing extubation failure compared to nCPAP.

\section{Cardiovascular disorders}

Patent ductus arteriosus (PDA) increases the risk of BPD, necrotizing enterocolitis (NEC) or the need for surgical ligation. Indomethacin therapy is the standard treatment for medical ligation of PDA. Ibuprofen and paracetamol therapies are the alternative treatments for PDA. There were no significant differences between paracetamol and either ibuprofen or indomethacin in the failure to close a PDA in preterm or low birth weight infants. However, gastrointestinal bleeding was lower in the paracetamol group versus the ibuprofen group [RR $(95 \% \mathrm{Cl}) 0.28(0.12,0.69)]$. The serum levels of creatinine were lower in the paracetamol group compared with either the ibuprofen or indomethacin group. Platelet counts and daily urine output were higher in the paracetamol group compared with either the ibuprofen or indomethacin group. ${ }^{31}$ Therefore, paracetamol is an alternative treatment if a neonate has a bleeding tendency or renal insufficiency. However, long-term neurodevelopmental outcomes should be a concern following prenatal and postnatal exposure to paracetamol which needs more trials.

\section{Gastrointestinal tract disorders}

Human milk feeding, prebiotics, prebiotics, synbiotics (probiotics and prebiotics), and lactoferrin make a balance in the intestinal microbiome and prevent NEC. ${ }^{32-34}$ Evidencebased medicine, synbiotics, and probiotics can decreased NEC but not prebiotics alone. ${ }^{35}$ Probiotics decreased the incidence of "all-cause mortality"36-39, "NEC stage II or greater", and "late-onset sepsis" 40 in preterm neonates. Strain-specific sub-meta-analyses showed a significant effect of probiotic mixtures and bifidobacteria on NEC. ${ }^{37}$ However, large and recent randomized controlled trials found no differences in the incidence of death, NEC, sepsis, or growth in preterm neonates who were given probiotics (Bifidobacterium lactis or B. longum or both $^{41}$ or $B$. breve ${ }^{42}$ ) compared to placebo. Enteral lactoferrin supplementation, with or without probiotics, decreased "late-onset sepsis" and "NEC stage II or III" in preterm infants without adverse effects. ${ }^{43}$

\section{Sepsis}

Chorioamnionitis or intra-amniotic infection is associated with significant maternal, perinatal, and long-term adverse outcomes. "Intrauterine inflammation or infection or both" can be abbreviated as "Triple I"44,45 and used instead of chorioamnionitis. The definition and treatment of clinical chorioamnionitis and suspected Triple I following new evidence are given in Table 1.44,45

Administration of intravenous immunoglobulin (IVIG) for prophylaxis showed a significant reduction in sepsis $[R R(95 \% \mathrm{Cl}) 0.85(0.74,0.98)]$ from $17.2 \%$ to $14.5 \%$ in preterm and/or low birth weight infants. ${ }^{46}$ However, there were no statistically significant differences in mortality from infection for either prophylaxis or treatment with IVIG administration. ${ }^{46,47}$ Moreover, IgM-enriched IVIG did not significantly reduce mortality during hospital stay in infants with suspected infection. Routine administration of IVIG or IgM-enriched IVIG to prevent mortality in infants with suspected or proven neonatal infection is not recommended. ${ }^{47}$ 
Table 1 Comparison of definition and treatment in healthy-appearing or asymptomatic neonates between clinical chorioamnionitis and suspected Triple I

\begin{tabular}{|c|c|c|}
\hline Scope & Clinical chorioamnionitis & Suspected Triple I \\
\hline \multirow[t]{10}{*}{ Definition } & $\begin{array}{l}\text { 1. Presence of maternal fever of greater than } \\
38{ }^{\circ} \mathrm{C} \text { and }\end{array}$ & $\begin{array}{l}\text { 1. Maternal oral temperature } 39.0{ }^{\circ} \mathrm{C} \text { or greater on any one occasion } \\
\text { without a clear source (if the oral temperature is } 38.0-39.0^{\circ} \mathrm{C} \text {, }\end{array}$ \\
\hline & 2. At least 2 of the following criteria: & repeat the measurement in 30 minutes; if the repeat value remains \\
\hline & 2.1 Maternal leukocytosis (greater than & at least $38.0^{\circ} \mathrm{C}$, it is documented fever) \\
\hline & 15,000 cells $\left./ \mathrm{mm}^{3}\right)$ & 2. Any of the following: \\
\hline & 2.2 Maternal tachycardia (greater than 100 & 2.1 Baseline fetal tachycardia (greater than 160 beats per min for \\
\hline & beats/minute) & 10 min or longer, excluding accelerations, decelerations, and \\
\hline & 2.3 Fetal tachycardia (greater than 160 & periods of marked variability) \\
\hline & beats/minute) & 2.2 Maternal white blood cell count greater than 15,000 per $\mathrm{mm}^{3}$ in \\
\hline & 2.4 Uterine tenderness & the absence of corticosteroids \\
\hline & 2.5 Foul odor of the amniotic fluid & 2.3 Definite purulent fluid from the cervical os \\
\hline \multirow[t]{4}{*}{ Treatment } & -require antimicrobial agents soon after birth & -Gestational age less than 35 weeks: work-up (complete blood count \\
\hline & and independent on gestational age and & and C-reactive protein) and empirical antimicrobial prophylaxis \\
\hline & results of initial complete blood count and & -Gestational age 35 weeks or greater: observe and re-evaluation \\
\hline & C-reactive protein & (close monitor within 6 hours until observe 48 hours of life) \\
\hline
\end{tabular}

Prophylactic oral/topical non-absorbed antifungal agents $[R R(95 \% \mathrm{Cl}) 0.20(0.14,0.27)]^{48}$ and prophylactic

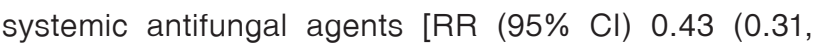
0.59) $]^{49}$ found a statistically significant reductions in the incidence of invasive fungal infection (IFI) in VLBW infants from $31.1 \%$ to $3.8 \%$ and $12.9 \%$ to $6.3 \%$, respectively. However, the incidence of IFI was very high in the control groups. The incidence of IFI in VLBW infants at Songklanagarind Hospital was $2.0 \%$ which was lower than the intervention group. Therefore, the routine prophylaxis of both administrations needs an understanding of the local epidemiology.

In conclusion, neonatal sepsis should be considered differently between clinical trial efficacy and real-world effectiveness including the local epidemiology.

\section{Conclusion}

Evidence-based practice is imperative care to improve the outcomes. Besides reduced mortality, longterm morbidities or neurodevelopmental outcomes should be the concerns for the best quality of life. Better outcomes in preterm infants have a high cost-effectiveness for long life.

\section{References}

1. Thatrimontrichai A. Best practice of neonatal care in Canada. Songkla Med J 2014;32:55-62.

2. Thatrimontrichai A. Care of preterm infant in Canada. Songkla Med J 2014;32:117-28.

3. Shepherd E, Salam RA, Middleton P, Makrides M, Mclntyre S, Badawi N, et al. Antenatal and intrapartum interventions for preventing cerebral palsy: an overview of Cochrane 
systematic reviews. Cochrane Database Syst Rev 2017;8: CD012077.

4. Zeng $X$, Xue $Y$, Tian Q, Sun R, An R. Effects and safety of magnesium sulfate on neuroprotection: a meta-analysis based on PRISMA guidelines. Medicine (Baltimore) 2016;95: e2451.

5. The American College of Obstetricians and Gynecologists Committee on Obstetric Practice Society for Maternal-Fetal Medicine. Committee Opinion No 652: Magnesium Sulfate Use in Obstetrics. Obstet Gynecol 2016;127:E52-3.

6. Fischer HS, Reibel NJ, Buhrer C, Dame C. Prophylactic early erythropoietin for neuroprotection in preterm infants: a metaanalysis. Pediatrics 2017;139. doi: 10.1542/peds.2016-4317.

7. Crowther CA, Middleton PF, Voysey M, Askie L, Duley L, Pryde $P G$, et al. Assessing the neuroprotective benefits for babies of antenatal magnesium sulphate: an individual participant data meta-analysis. PLoS Med 2017;14. doi: 10.1371/journal. pmed. 1002398

8. Jacobs SE, Berg M, Hunt R, Tarnow-Mordi WO, Inder TE, Davis PG. Cooling for newborns with hypoxic ischaemic encephalopathy. Cochrane Database Syst Rev 2013;1:CD003311.

9. Laptook AR, Shankaran S, Tyson JE, Munoz B, Bell EF, Goldberg RN, et al. Effect of therapeutic hypothermia initiated after 6 hours of age on death or disability among newborns with hypoxic-ischemic encephalopathy: a randomized clinical trial. JAMA 2017;318:1550-60.

10. Shankaran S, Laptook AR, Pappas A, McDonald SA, Das A, Tyson JE, et al. Effect of depth and duration of cooling on death or disability at age 18 months among neonates with hypoxic-ischemic encephalopathy: a randomized clinical trial. JAMA 2017;318:57-67.

11. Azzopardi D, Strohm B, Marlow N, Brocklehurst P, Deierl A, Eddama $O$, et al. Effects of hypothermia for perinatal asphyxia on childhood outcomes. N Engl J Med 2014;371: 140-9.

12. Doyle LW, Cheong JL, Ehrenkranz RA, Halliday HL. Late (>7 days) systemic postnatal corticosteroids for prevention of bronchopulmonary dysplasia in preterm infants. Cochrane Database Syst Rev 2017;10:CD001145.

13. Doyle LW, Cheong JL, Ehrenkranz RA, Halliday HL. Early (<8 days) systemic postnatal corticosteroids for prevention of bronchopulmonary dysplasia in preterm infants. Cochrane Database Syst Rev 2017;10:CD001146.
14. Shah VS, Ohlsson A, Halliday HL, Dunn M. Early administration of inhaled corticosteroids for preventing chronic lung disease in very low birth weight preterm neonates. Cochrane Database Syst Rev 2017;1:CD001969.

15. Onland $W$, Offringa $M$, van Kaam $A$. Late ( $>/=7$ days) inhalation corticosteroids to reduce bronchopulmonary dysplasia in preterm infants. Cochrane Database Syst Rev 2017;8:CD002311.

16. Shah SS, Ohlsson A, Halliday HL, Shah VS. Inhaled versus systemic corticosteroids for the treatment of bronchopulmonary dysplasia in ventilated very low birth weight preterm infants. Cochrane Database Syst Rev 2017;10: CD002057.

17. Henderson-Smart DJ, De Paoli AG. Methylxanthine treatment for apnoea in preterm infants. Cchrane Database Syst Rev 2010; 12:CD000140

18. Henderson-Smart DJ, Steer P. Prophylactic caffeine to prevent postoperative apnea following general anesthesia in preterm infants. Cochrane Database Syst Rev 2001;4: CD000048.

19. Henderson-Smart DJ, Davis PG. Prophylactic methylxanthines for endotracheal extubation in preterm infants. Cochrane Database Syst Rev 2010;12:CD000139.

20. Henderson-Smart DJ, De Paoli AG. Prophylactic methylxanthine for prevention of apnoea in preterm infants. Cochrane Database Syst Rev 2010;12:CD000432.

21. Schmidt B, Roberts RS, Davis P, Doyle LW, Barrington KJ, Ohlsson A, et al. Caffeine therapy for apnea of prematurity. N Engl J Med 2006;354:2112-21.

22. Schmidt B, Roberts RS, Davis P, Doyle LW, Barrington KJ, Ohlsson A, et al. Long-term effects of caffeine therapy for apnea of prematurity. N Engl J Med 2007;357:1893-902.

23. Schmidt B, Anderson PJ, Doyle LW, Dewey D, Grunau RE, Asztalos EV, et al. Survival without disability to age 5 years after neonatal caffeine therapy for apnea of prematurity. JAMA 2012;307:275-82.

24. Schmidt B, Roberts RS, Anderson PJ, Asztalos EV, Costantini L, Davis PG, et al. Academic performance, motor function, and behavior 11 years after neonatal caffeine citrate therapy for apnea of prematurity: an 11-year follow-up of the cap randomized clinical trial. JAMA Pediatr 2017;171:564-72.

25. Murner-Lavanchy IM, Doyle LW, Schmidt B, Roberts RS, Asztalos EV, Costantini L, et al. Neurobehavioral outcomes 
11 years after neonatal caffeine therapy for apnea of prematurity. Pediatrics 2018;141. doi: 10.1542/peds.2017-4047.

26. Ferguson KN, Roberts CT, Manley BJ, Davis PG. Interventions to improve rates of successful extubation in preterm infants: a systematic review and meta-analysis. JAMA Pediatr 2017; 171:165-74

27. Mukerji A, Dunn M. High-frequency ventilation as a mode of noninvasive respiratory support. Clin Perinatol 2016;43:725-40.

28. Binmanee A, El Helou S, Shivananda S, Fusch C, Mukerji A. Use of high noninvasive respiratory support pressures in preterm neonates: a single-center experience. J Matern Fetal Neonatal Med 2017;30:2838-43.

29. De Luca D, Dell'Orto V. Non-invasive high-frequency oscillatory ventilation in neonates: review of physiology, biology and clinical data. Arch Dis Child Fetal Neonatal Ed [serial on the Internet]. 2016 Nov [cited 2018 Dec 9]; 101(6). Available from: https://fn.bmj.com/content/101/6/F565.long

30. Praud JP, Fortin-Pellerin E. Non-invasive high-frequency oscillatory ventilation for preterm newborns: the time has come for consideration. Pediatr Pulmonol 2017;52:1526-8

31. Ohlsson A, Shah PS. Paracetamol (acetaminophen) for patent ductus arteriosus in preterm or low birth weight infants. Cochrane Database Syst Rev 2018;4:CD010061.

32. Vongbhavit K, Underwood MA. Prevention of necrotizing enterocolitis through manipulation of the intestinal microbiota of the premature infant. Clin Ther 2016;38:716-32.

33. Johnson-Henry KC, Abrahamsson TR, Wu RY, Sherman PM. Probiotics, prebiotics, and synbiotics for the prevention of necrotizing enterocolitis. Adv Nutr 2016;7:928-37.

34. Thatrimontrichai A. Gut microbiota and probiotics in neonate. Songkla Med J 2017;35:101-8.

35. Dilli D, Aydin B, Fettah ND, Ozyazici E, Beken S, Zenciroglu A, et al. The propre-save study: effects of probiotics and prebiotics alone or combined on necrotizing enterocolitis in very low birth weight infants. J Pediatr 2015;166:545-51.

36. AlFaleh K, Anabrees J. Probiotics for prevention of necrotizing enterocolitis in preterm infants. Cochrane Database Syst Rev 2014;4:CD005496.

37. Aceti A, Gori D, Barone G, Callegari ML, Di Mauro A, Fantini MP, et al. Probiotics for prevention of necrotizing enterocolitis in preterm infants: systematic review and meta-analysis. Ital J Pediatr 2015;41:89.
38. Lau CS, Chamberlain RS. Probiotic administration can prevent necrotizing enterocolitis in preterm infants: a meta-analysis. J Pediatr Surg 2015;50:1405-12.

39. Olsen R, Greisen G, Schroder M, Brok J. Prophylactic probiotics for preterm infants: a systematic review and metaanalysis of observational studies. Neonatology 2016;109:10512.

40. Rao SC, Athalye-Jape GK, Deshpande GC, Simmer KN, Patole SK. Probiotic supplementation and late-onset sepsis in preterm infants: a meta-analysis. Pediatrics 2016;137: e20153684.

41. Hays S, Jacquot A, Gauthier H, Kempf C, Beissel A, Pidoux O, et al. Probiotics and growth in preterm infants: a randomized controlled trial, PREMAPRO study. Clin Nutr 2016;35:802-11.

42. Costeloe K, Hardy P, Juszczak E, Wilks M, Millar MR, Probiotics in preterm Infants study collaborative group. Bifidobacterium breve BBG-001 in very preterm infants: a randomised controlled phase 3 trial. Lancet 2016;387:649-60.

43. Pammi M, Suresh G. Enteral lactoferrin supplementation for prevention of sepsis and necrotizing enterocolitis in preterm infants. Cochrane Database Syst Rev 2017;6:CD007137.

44. Randis TM, Polin RA, Saade G. Chorioamnionitis: time for a new approach. Curr Opin Pediatr 2017;29:159-64.

45. Higgins RD, Saade G, Polin RA, Grobman WA, Buhimschi IA, Watterberg $\mathrm{K}$, et al. Evaluation and management of women and newborns with a maternal diagnosis of chorioamnionitis: summary of a workshop. Obstet Gynecol 2016;127:426-36.

46. Ohlsson A, Lacy JB. Intravenous immunoglobulin for preventing infection in preterm and/or low birth weight infants. Cochrane Database Syst Rev 2013;7:CD000361.

47. Ohlsson A, Lacy JB. Intravenous immunoglobulin for suspected or proven infection in neonates. Cochrane Database Syst Rev 2015;3:CD001239.

48. Austin N, Cleminson J, Darlow BA, McGuire W. Prophylactic oral/topical non-absorbed antifungal agents to prevent invasive fungal infection in very low birth weight infants. Cochrane Database Syst Rev 2015;10:CD003478.

49. Cleminson J, Austin N, McGuire W. Prophylactic systemic antifungal agents to prevent mortality and morbidity in very low birth weight infants. Cochrane Database Syst Rev 2015; 10:CD003850. 